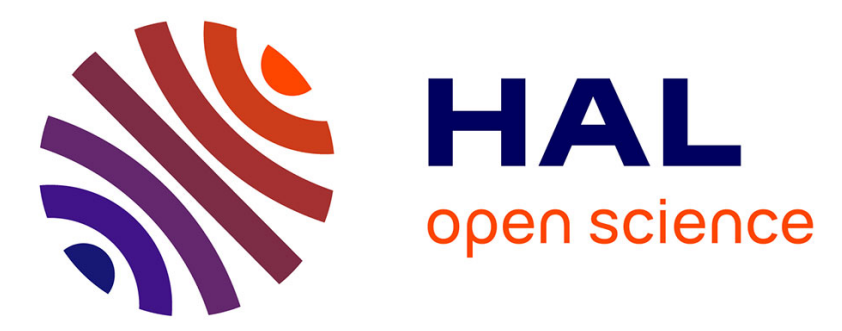

\title{
Rural populations of the red fox Vulpes vulpes show little evidence of reproductive senescence
}

\author{
Nicolas Lieury, Nolwenn Drouet-Hoguet, Sandrine Ruette, Sébastien \\ Devillard, Michel Albaret, Alexandre Millon
}

\section{- To cite this version:}

Nicolas Lieury, Nolwenn Drouet-Hoguet, Sandrine Ruette, Sébastien Devillard, Michel Albaret, et al.. Rural populations of the red fox Vulpes vulpes show little evidence of reproductive senescence. Mammalian Biology: Zeitschrift für Säugetierkunde, 2017, 87, pp.146 - 151. 10.1016/j.mambio.2017.08.008 . hal-01766430

\section{HAL Id: hal-01766430 \\ https://hal.science/hal-01766430}

Submitted on 13 Apr 2018

HAL is a multi-disciplinary open access archive for the deposit and dissemination of scientific research documents, whether they are published or not. The documents may come from teaching and research institutions in France or abroad, or from public or private research centers.
L'archive ouverte pluridisciplinaire HAL, est destinée au dépôt et à la diffusion de documents scientifiques de niveau recherche, publiés ou non, émanant des établissements d'enseignement et de recherche français ou étrangers, des laboratoires publics ou privés. 


\section{Accepted Manuscript}

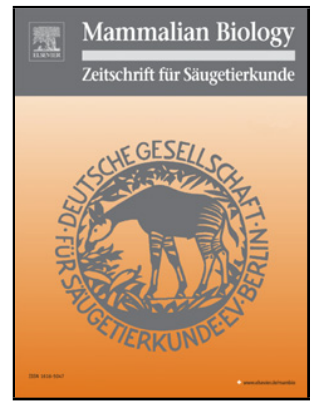

Title: Rural populations of the red fox Vulpes vulpes show little evidence of reproductive senescence

Authors: Nicolas Lieury, Nolwenn Drouet-Hoguet, Sandrine Ruette, Sébastien Devillard, Michel Albaret, Alexandre Millon

PII: $\quad$ S1616-5047(17)30079-4

DOI: $\quad$ http://dx.doi.org/10.1016/j.mambio.2017.08.008

Reference: $\quad$ MAMBIO 40931

To appear in:

Received date: $\quad 28-2-2017$

Accepted date: $\quad$ 25-8-2017

Please cite this article as: Lieury, Nicolas, Drouet-Hoguet, Nolwenn, Ruette, Sandrine, Devillard, Sébastien, Albaret, Michel, Millon, Alexandre, Rural populations of the red fox Vulpes vulpes show little evidence of reproductive senescence.Mammalian Biology http://dx.doi.org/10.1016/j.mambio.2017.08.008

This is a PDF file of an unedited manuscript that has been accepted for publication. As a service to our customers we are providing this early version of the manuscript. The manuscript will undergo copyediting, typesetting, and review of the resulting proof before it is published in its final form. Please note that during the production process errors may be discovered which could affect the content, and all legal disclaimers that apply to the journal pertain. 
Reproductive senescence in the red fox

\section{Rural populations of the red fox Vulpes vulpes show little evidence of}

\section{reproductive senescence}

Running title: Reproductive senescence in the red fox

Nicolas Lieury ${ }^{\mathrm{a}, \mathrm{b}}$, Nolwenn Drouet-Hoguet ${ }^{\mathrm{c}}$, Sandrine Ruette ${ }^{\mathrm{c}}$, Sébastien Devillard ${ }^{\mathrm{b}}$, Michel Albaret $^{\mathrm{c}} \&$ Alexandre Millon ${ }^{\mathrm{a}}$

aAix Marseille Univ, CNRS, IRD, Avignon Université, IMBE, Institut Méditerranéen de Biodiversité et d'Ecologie marine et continentale, Technopôle Arbois-Méditerranée, Bât. Villemin - BP 80, F-13545 Aix-en-Provence cedex 04, France

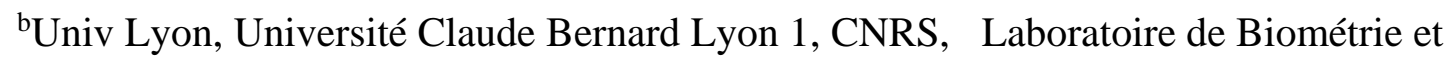
Biologie Evolutive, F-69100, Villeurbanne, France.

${ }^{\mathrm{c} O f f i c e}$ National de la Chasse et de la Faune Sauvage, Unité Prédateurs Animaux Déprédateurs, Montfort, F-01330 Birieux, France

*corresponding author: Sandrine Ruette, sandrine.ruette@ oncfs.gouv.fr, Tel. +334 749831 89, fax: +33474981411

Abstract: 222

Word count: 5561

Figures: 2

Tables: 3 
Reproductive senescence in the red fox

\begin{abstract}
The ageing theory predicts fast and early senescence for fast-living species. We investigated whether the pattern of senescence of a medium-sized, fast-living and heavily-culled mammal, the red fox (Vulpes vulpes), fits this theoretical prediction. We used cross-sectional data from a large-scale culling experiment of red fox conducted over six years in five study sites located in two regions of France to explore the age-related variation in reproductive output. We used both placental scars and embryos counts from 755 vixens' carcasses aged by the tooth cementum method (age range: 1-10), as proxies for litter size. Mean litter size per vixen was 4.7 \pm 1.4. Results from Generalized Additive Mixed Models revealed a significant variation of litter size with age. Litter size peaked at age 4 with $5.0 \pm 0.2$ placental scars and decreased thereafter by 0.5 cubs per year. Interestingly, we found a different age-specific variation when counting embryos which reached a plateau at age 5-6 (5.5 \pm 0.2$)$ and decreased slower than placental scars across older ages, pointing out embryo resorption as a potential physiological mechanism of reproductive senescence in the red fox. Contrary to our expectation, reproductive senescence is weak, occurs late in life and takes place at an age reached by less than $11.7 \%$ of the population such that very few females exhibit senescence in these heavily culled populations.
\end{abstract}

\title{
Keywords
}

Litter size, Vulpes vulpes, Placental scar count, Embryo count, Reproductive senescence

\section{Introduction}

Senescence, or ageing is the gradual deterioration of physical condition and cellular functioning, which results in a decline in fitness with age (Kirkwood and Austad, 2000; Sharp and Clutton-Brock, 2010). Ageing can be expressed as a reduction in survival probability 
Reproductive senescence in the red fox

and/or a deterioration of reproductive efficiency, including decrease in the probability to give birth and reduced litter size. It is now recognized that both reproductive and actuarial senescence are widespread in the wild. Senescence rate greatly vary across individuals (Bouwhuis et al., 2010), populations (Lemaître et al., 2015) and species (Jones et al., 2008; Nussey et al., 2013). Life-history theory provides a framework for predicting the variability of ageing across species. Major life-history traits, such as the age at first reproductive event, reproductive lifespan and number and size of offspring, vary across species, even when bodysize is controlled for (Bielby et al., 2007; Gittleman, 1986; Harvey and Clutton-Brock, 1985; Read and Harvey, 1989; Stearns, 1983). Such response led to the concept of "fast-slow continuum" of life-history variations, which categorises species from short-lived and highly reproductive species to long-lived species showing reduced reproductive output (Cody, 1966; Cole, 1954; Dobzhansky, 1950; Gaillard et al., 1989; Lack, 1947; Promislow and Harvey, 1990; Read and Harvey, 1989; Stearns, 1983). As synthesised by Gaillard et al. (2016), the fast-slow continuum can be interpreted as the range of possible solutions to the trade-off between reproduction and survival. The variation in ageing pattern along the continuum of senescence has been assessed by Jones et al. (2008). These authors showed that both agespecific mortality and fertility patterns were strongly heterogeneous among vertebrates. Using data from 20 populations of intensively monitored vertebrates, they concluded that ageing is influenced by the species' position on the fast-slow continuum, which sets the principles of a continuum of senescence that predicts fast and early senescence for fast-living species (Jones et al., 2008).

The red fox Vulpes vulpes is a medium-sized carnivore, known to have a fast reproductive rate with high productivity and early sexual maturity (Englund, 1970; Harris, 1979; Harris and Smith, 1987; Ruette and Albaret, 2011). According to the life history theory of ageing, red fox is therefore expected to display an early and fast senescence. To date, the demography of red 
Reproductive senescence in the red fox

fox has been mainly studied in anthropogenic contexts, and evidence of senescence in this species is mixed (Artois et al., 1982; Cavallini and Santini, 1996; Harris, 1979; Harris and Smith, 1987; Marlow et al., 2000).

In France, red fox are hunted or even culled when locally classified as a pest species preying upon farmed and game species. Between 2002 and 2011, we conducted a fox culling experiment to measure the impact of removals on fox population dynamics in two rural regions (Lieury et al., 2015). This landscape-scale experiment thus provided a unique opportunity to study the age-specific variation in reproduction. We addressed the variation in reproductive output with age, expecting an early onset of senescence. Recent papers have recommended a better comprehension of heterogeneity among life history traits in the wild, so as to improve the detection of cryptic senescence and its underlying mechanisms (Hewison and Gaillard, 2001; Massot et al., 2011; Nussey et al., 2013). Thus, looking at a single reproductive trait might be misleading regarding senescence. Therefore we analysed two proxies of litter size (counts of placental scars and embryos) which may shed light on the underlying physiology of reproductive senescence.

\section{Material and Methods}

\section{Study area and data collection}

Data were obtained from culling campaigns performed as part of a large-scale culling experiment of the red fox in two French regions over six years (Lieury et al., 2015). The carcasses of 899 vixens were collected in five distinct rural study areas (average size: $246 \pm$ $53 \mathrm{~km}^{2}$; Fig. 1). All sites were located in the same range latitude: in Brittany (sites A, B and $\mathrm{C} ; \geq 10 \mathrm{~km}$ apart; $48^{\circ} 10^{\prime} \mathrm{N}, 03^{\circ} 00^{\prime} \mathrm{W}$ ) and Champagne (sites D and E separated by the Seine River; $\left.48^{\circ} 40^{`} \mathrm{~N}, 04^{\circ} 20^{\prime} \mathrm{E}\right)$. Brittany landscape was dominated by bocage mixing farming and arable lands, with little forested area. In contrast, Champagne sites presented open field 
Reproductive senescence in the red fox

systems (mostly cereals and vineyard) and a larger forest cover compared to Brittany. The study took place from 2002 to 2011 but was not synchronous across all five sites. Hunting occurred between October and February, and trapping occurred between December and April. Culling at the den occurred in April. Night shooting occurred only in sites D-E between December and May (see Lieury et al., 2015 for details).

\section{Reproductive parameters}

An estimation of the litter size could be made for 755 reproductive females with undamaged uterus among the 899 vixens collected (84\%; Table 1). We used the number of embryos and the number of placental scars as two proxies for litter size (respectively on 394 and 361 individuals). When counting embryos only prenatal losses during early-pregnancy stages are considered while with placental scar counts, all losses between implantation and birth are taken into account. For pregnant females (i.e. females which were culled from February to April), embryos were counted. For the others, uteri were collected 12-48 $\mathrm{h}$ after the death of the animal, and soaked in water before freezing and stored at $-20^{\circ} \mathrm{C}$ until examination. Uteri horns were opened longitudinally and examined for placental scars (Elmeros et al., 2003; Lindström, 1994). When the evaluation of litter size was questionable, we used a staining method to facilitate the identification of active placental scars (Ruette and Albaret, 2011). The staining method allows for the identification of atypical scars, i.e. with a singular aspect when compared to others from the same uterus or from other uteri at the same period of examination. However it does not permit the distinction of scars that could have persisted from earlier pregnancies from those that have been due to resorption or abortion (Ruette et Albaret, 2011). So, we did not estimate resorption rates from atypical placental scars counts. 
Reproductive senescence in the red fox

The age of foxes at death was determined from the carcasses based on the number of annual growth lines visible in the tooth cementum, the date of death and the expected date of birth on April $1^{\text {st }}$ (Ruette and Albaret, 2011). Canine teeth, or premolar teeth when canines were unavailable or damaged, were extracted from the lower jaw following Matson's laboratories (Milltown, MT, USA) procedures (Harris, 1978). Foxes were assigned to age-classes based on their recruitment into the adult population on February $1^{\text {st }}$ of the year following birth (i.e. at the age of 10 months old). Animals between 10 and 22 months of age were classified as ageclass 1 (yearlings) whereas older ones were classified as age-class 2, 3, and up to 10.

\section{Modelling and data analysis}

Although the Poisson distribution has been often applied to the counts of offspring such as litter size, the Gaussian distribution actually fits better such reproductive data that are typically associated with a narrower variance than expected under a Poisson distribution (Devenish-Nelson et al., 2013a; McDonald \& White 2010). We thus developed a model for age-dependent variation in litter size accounting for both among-sites and among-years variability (Artois et al., 1982; Devenish-Nelson et al., 2013b; Ruette and Albaret, 2011) with a Gaussian distribution of error.

We used generalized additive mixed models (GAMM; Wood, 2006) to explore the relationship between vixen age and litter size without a priori hypothesis on its shape (Jones et al., 2008). Year and geographic area (study sites, 'Site', or region, 'Region') were tested as random factors to account for their potential confounding effects on litter size. Litter size may indeed depend on i) variations in habitat quality among sites or regions, ii) inter-annual variations in climate conditions or resources availability and iii) spatio-temporal variations of population densities between sites or regions. 
Reproductive senescence in the red fox

Finally, we also tested the effect of the type of measure for litter size (i.e. placental scars $v s$. embryos) by adding a fixed effect 'Type' in the model.

We thus developed a full GAMM for the variations of litter size (LS) as follows:

$\mathrm{LS}=\mathrm{s}($ Age $) \times$ Type + Age $\mid$ Site $+1 \mid$ Year,

The bars indicate the addition of a random effect of the 'Year' on the intercept (1) or of the site on the slope (Age). The parameterization $s($ Age $) \times$ Type denotes that the non-linear effect of vixen age was modelled independently for each type of the litter size proxy 'Type'.

Following Zuur et al. (2009), we first started from the full random model and evaluated whether the age-specific variation in LS was similar among sites (random parameterisations: Age|Site vs. 1|Site), whether the spatial variation among regions was negligible when compared to the spatial variation among sites (1|Region vs. 1|Site) and whether the random effect of the year (1|Year) was important. According to Zuur et al. (2009), parameters were estimated using Restricted Maximum Likelihood (REML) for random effects and Maximum Likelihood (ML) for fixed effects. Model selection was based on the AICc (Akaike Information Criterion corrected from small sample size; Burnham and Anderson, 2002). Once the random effects were selected, we performed an AICc-based model selection of fixed effects (Zuur et al., 2009) to test whether the type of measure affected age-specific variation in LS.

Finally, we estimated the rate of senescence by using least-squares linear regression models fitted through the mean values of each litter size, from the onset of senescence onwards, as predicted by the most parsimonious GAMM. Each point was weighted by the inverse of the variance so as to account for the small number of individuals in the oldest age classes.

All analyses were carried out in R.2.15.1 using packages mgcv and AICcmodavg (R Development Core Team, 2012; Wood, 2006). Descriptive statistics of the data were presented as mean $\pm 1 \mathrm{SD}$ and model estimates as mean $\pm 1 \mathrm{SE}$. 
Reproductive senescence in the red fox

\section{Results}

Pooled over sites, years and age, litter size averaged $4.9 \pm 1.4$ when based on embryo counts and $4.5 \pm 1.4$ from counts of placental scars (see Table 2 for detailed results by age class). From GAMM, all models including the random effects of the Year, the Site or the Region and the fixed effect of Age and Type had substantial support $(\triangle A I C c<2$, Table 3$)$. We retained the simplest of those models (Table

3). Placental scars count increased up to $5.0 \pm 0.2$ at the age of 4 (black line and dots in Fig. 2). From the age of 4 onwards, it significantly declined at a rate of senescence of $0.5 \pm 0.02$ cubs per year (Fig. 2). This pattern was consistent across study areas (random effects '1|Site' retained; Table 3.A), thereby suggesting that senescence pattern is likely to be a generalized process in red fox populations. We found divergence in senescence patterns between the two proxies of litter size (fixed effect s(Age)×Type retained; Table 3.B). Embryo counts peaked at age five but the rate of senescence in embryo counts afterwards was much reduced compared to placental scars $(0.1 \pm 0.01$ cubs per year; Fig. 2$)$. Finally, only a small proportion of females were killed after the age of 4 and 5 (11.7 and 5.6\% respectively, median age at death: 2 years, Fig. 2), such that very few females exhibited senescence in these heavily culled populations.

\section{Discussion}

We took advantage of a large dataset collected over 10 years from a landscape-scale culling experiment in rural France, to investigate the deterioration in reproductive output with age in the red fox. Contrary to our expectation, our results revealed a weak and late reproductive senescence in this species. The onset of senescence occurred late (four years old) relatively to the age structure of the population (median age at death: two years old). The decline in litter 
Reproductive senescence in the red fox

size after four or five years old depending on the proxy used was significant but clearly more pronounced for placental scars count than for embryos count, suggesting increased embryo resorption as a likely physiological mechanism of senescence. This weak and late senescence concerned very few females in the populations (i.e. less than $11.7 \%$ of the females in the population reached the age of the onset of senescence) so that the impact of senescence on the dynamics of these heavily culled populations is likely to be negligible.

\section{Limits inherent to post-mortem and cross-sectional data for investigating senescence}

Monitoring reproductive performance in red fox is challenging on a large scale, due to its nocturnal, cryptic and elusive behaviour. We used post-mortem examination of carcasses to measure litter size and age. Although these methods may overcome some of the challenges of studying reproduction in free-ranging carnivore populations, we are aware of the inherent weaknesses in their applications. First, we estimated red fox age from cementum annuli lines in teeth. Although the method is widely used in carnivores studies such as red fox (Harris et al., 1992) or hyaena (Van Horn et al., 2003), misclassification has been noted due to some animals that did not develop a cementum line in one year (Grau et al., 1970 on raccoons; King, 1991 on stoats; Matson and Matson, 1993). Deposition of cementum annuli and tooth wear may also vary with diet, season and region (Costello et al., 2004 on black bears). The method has not been applied on red foxes of known age. Thus we could not rule out some misclassifications although not quantifiable. Working with dead animals, we used placental scars and embryos counts as proxies for litter size. Placental scars counts provide a possible overestimate of litter size, due to embryos resorption, prenatal mortality and stillborn litters (Vos, 1994; Elmeros et al., 2003). Inversely in a certain time postpartum, litter size might be underestimated by placental scars count due to the regeneration of uterine tissues (Harris, 
Reproductive senescence in the red fox

1979; Harris and Smith, 1987; Heydon and Reynolds, 2000; Lindström, 1994; Marlow et al., 2000; McIlroy et al., 2001; Ruette and Albaret, 2011).

Our approach relies on the use of data from large-scale culling experiments to investigate senescence in five population replicates. Yet, the inference of senescence from life-table studies using cross-sectional data has been questionable for a long time. Indeed, the needs to consider sources of heterogeneity, such as unequal probability of sampling, individual heterogeneity, climate, density or early life conditions, advocate for following individuals throughout their life (Gaillard et al., 1994, 1989; Nussey et al., 2013; Reid et al., 2003). However, as non-selective methods of culling (trapping and hunting) were used, there is no reason to expect bias toward low or high reproductive individuals, since the age of adult's foxes could not be visually assessed. Moreover, we took into account the variability between populations by using samples from two contrasted regions and over several years.

Nevertheless, it is important to consider both within (improvement, senescence) and betweenindividuals (selective appearance and disappearance) process in the estimation of patterns of age-dependent reproduction (Reid et al., 2003; Van de Pol and Verhulst, 2006). For instance, if individuals with high reproduction have poorer survival, mean reproduction may decline across older age because only individuals that invest little on reproduction survive. Selective disappearance has thus been found to partly mask the age-related changes in reproductive traits in ungulates (Nussey et al., 2008, 2006).

We have no possibility to check for that kind of individual heterogeneity, determined by genetic and/or natal environment conditions. However, we found senescence in both traits i.e. numbers of placental scars and embryos and have no reason to expect a different sampling bias in vixens collected before or after parturition. Moreover, we did not observe a reduction in litter size variance with age expected in case of selective appearance or disappearance process (result not shown). 
Reproductive senescence in the red fox

Besides, cross-sectional data are not systematically biased by individual heterogeneity and earlier studies revealing reproductive senescence from such data had been a posteriori validated by longitudinal data (Hanks, 1972). Hence, we are confident that our approach provides a relatively accurate picture of the age-related pattern in red fox reproduction. However, we call for long-term individual-based time series throughout longitudinal datasets to confirm senescence in free-ranging red fox populations.

\section{Reproductive senescence in the red fox}

Age-related reproductive output in red fox has long been discussed, but without reaching unanimous findings regarding senescence. Our results confirmed the increase of litter size with age among the young age-classes with a maximum reached at the age of 4-5 years old (see also Englund, 1970; Harris, 1979; Lindström, 1989). However, the decrease in litter size for older vixens has rarely been evidenced (Artois et al., 1982; Cavallini and Santini, 1996; Marlow et al., 2000). Moreover, litter size estimated from placental scars was even reported to be independent of age in several red foxes populations (France: Artois et al., 1982; Central Italy: Cavallini and Santini, 1996; Denmark: Elmeros et al., 2003; and in Western Australia: Marlow et al., 2000). Here we were able to reveal a weak senescence pattern in reproduction in vixens from five to ten years old, and that affects reproduction at a rate of one cub less every two years when considering placental scars. Harris (1979) and Harris and Smith (1987) described for the first time reproductive senescence in London urban fox population. In a sample of 192 vixens, litter size significantly decreased in their fifth and sixth breeding season. Our results obtained in rural areas where fox densities are lower, are in accordance with those results. Interestingly in South-East Australia, i.e. in a context of invasion, reproductive parameters peaked in fifth- and sixth-year vixens, but vixens over eight years of age produced as many cubs as first-year breeders did (McIlroy et al., 2001). 
Reproductive senescence in the red fox

Reproductive senescence has been identified in several natural populations of mammals including ungulates, primates and domestic livestock (Beehner, 2006; Ericsson et al., 2001; Jones et al., 2008; Nussey et al., 2006; Promislow, 1991). To date only little evidence of reproductive senescence exists in carnivores, most of them focusing on long-lived species such as lions (Packer et al., 1988), bears (Schwartz et al., 2003; but see Dugdale et al., 2011 on badgers). Only recently, senescence has been detected in free-ranging American mink, Neovison vison, a short-lived species with early age at first parturition (Melero et al., 2015). The proposal formulated by Jones et al. (2008) that the magnitude of senescence is tightly associated with life history, mainly the slow-fast continuum, has been previously verified in populations of similar traits such as marmots (Berger et al., 2016), meerkats (Sharp and Clutton-Brock, 2010), ground squirrels (Broussard et al., 2003), opossums (Austad 1993), and badgers (Dugdale et al., 2011). Our findings provided evidence of weak reproductive senescence in the fast-living red fox, which occurred late (4-5 years old) relatively to the agestructure of our populations, and, therefore does not fully support the proposal of Jones et al. (2008). Furthermore, it concerned only very few females, since only a small proportion of vixens were killed after the age of 4 and 5.

\section{Increasing embryo resorption with age: a physiological mechanism underpinning} reproductive senescence?

Interestingly, senescence was more pronounced on placental scars than on the number of embryos. It suggested that gestation failure is the most likely cause of the decline in red fox litter size, rather than a decrease in ovulation rate. Spontaneous embryo resorption is an important issue in obstetrics, but also in livestock breeding and wildlife breeding programs. In wild species, increasing implantation failure with age has been identified in several taxa such as roe deer (Borg, 1970, Hewison and Gaillard, 2011). Accordingly, reproductive senescence 
Reproductive senescence in the red fox

resulted from a combination uterine defects and reduction in oocyte numbers in elephant (Hanks, 1972). The success of embryo to develop depends on a complex series of cellular and molecular mechanisms associated with hormonal balance (Cross et al., 1994; Finn, 1977). According to the disposal soma theory of ageing, individuals should invest less effort in the maintenance of somatic tissues for those that invested early in life, based on the best allocation of resources among the various metabolic tasks (Kirkwood, 1977; Kirkwood and Rose, 1991). In the case of red fox, the ageing of reproductive tracts (mainly uterus) probably plays an important role in the decrease of red fox litter size with age.

Finally, our study highlighted that reproductive senescence occurs in red fox populations, although being weak and occurring late in life. The consequences of reproductive senescence on red fox population dynamics might be negligible due to the low proportion of females in the population that reached the age at the onset of senescence. In the context of intensive removal through hunting and trapping acting on population densities (Lieury et al., 2015), a proper assessment of the effect of the variation in population density and removal pressure over time and populations on the reproductive performance is needed to investigate process such as compensatory reproduction.

\section{Acknowledgements}

We are grateful to the regional and local Hunter's associations, and we warmly thank all people involved in field activity. We are grateful to the regional and local Hunters' Associations, especially Y. Desmidt, J.-L. Pilard, P. Hecht, C. Mercuzot, J. Desbrosse, and C. Urbaniak for sustaining the program. We warmly thank F. Drouyer, B. Baudoux, N. Haigron, C. Mangeard, and T. Mendoza for efficient support in the fieldwork, our colleagues working on hares, especially Y. Bray and J. Letty and all local people in charge of hunting, and hunters 
Reproductive senescence in the red fox

and trappers who helped in counting and collecting foxes. This study was partially funded by the Regional Hunters' Association of Champagne-Ardenne, and the Hunters' Associations of Aube and Ille-et-Vilaine.

This work was supported by the Regional Hunters' Association of Champagne-Ardenne, and the Hunters' Associations of Aube and Ille-et-Vilaine.

\section{References}

Artois, M., Aubert, M.F.A., Gerard, Y., 1982. Reproduction du renard roux (Vulpes vulpes) en France: rythme saisonnier et fécondité des femelles. Acta Oecol. 3, 205-216.

Austad, S.N., 1993. Retarded senescence in an insular population of Virginia opossums (Didelphis virginiana). J. Zool. 229, 695-708.

Beehner, J.C., 2006. The ecology of conception and pregnancy failure in wild baboons. Behav. Ecol. 17, 741-750.

Berger, V., Lemaitre, J.-F., Dupont, P., Allainé, D., Gaillard, J.-M., Cohas, A., 2016. Agespecific survival in the socially monogamous alpines marmot (Marmota marmota): evidence of senescence. J. Mammal. 97, 992-1001.

Bielby, J., Mace, G.M., Bininda-Emonds, O.R., Cardillo, M., Gittleman, J.L., Jones, K.E., Orme, C.D., Purvis, A., 2007. The fast-slow continuum in mammalian life history: an empirical reevaluation. Am Nat 169, 748-757.

Borg, K., 1970. On mortality and reproduction of roe deer in Sweden during the period 194869. Viltrevy 7, 119-149.

Broussard, D.R., Risch, T.S., Dobson, F.S., Murie, J.O., 2003. Senescence and age-related reproduction of female Columbian ground squirrels. J. Anim. Ecol. 72, 212-219. 
Reproductive senescence in the red fox

Bouwhuis, S., Charmantier A., Verhulst S., Sheldon, B.C., 2010. Individual variation in rates of senescence: natal origin effects and disposable soma in a wild bird population. J. Anim. Ecol. 79, 1251-1261.

Burnham, K.P., Anderson, D.R., 2002. Model selection and multimodel inference: a practical information-theoric approach. $2^{\text {nd }}$ ed. Springer Verlag, New York, USA.

Cavallini, P., Santini, S., 1996. Reproduction of the red fox Vulpes vulpes in Central Italy. Ann. Zool. Fenn. 33, 267-74.

Cody, M.L., 1966. A general theory of clutch size. Evolution 20, 174-184.

Cole, L.C., 1954. The population consequences of life history phenomena. Quart. Rev. Biol. 29, 103-137.

Costello, C.M., Inman, K.H., Jones, D.E., Inman, R.M., Thompson, B.C., Quigley, H.B., 2004. Reliability of the cementum annuli technique for estimating age of black bears in New Mexico. Wildl. Soc. B 32, 169-176.

Cross, J.C., Werb, Z., Fisher, S.J., 1994. Implantation and the placenta: key pieces of the developmental puzzle. Science 266, 1508-1518.

Devenish-Nelson, E. S., Stephens, P. A., Harris, S., Soulsbury, C., Richards, S. A., $2013 a$. Does litter size variation affect models of terrestrial carnivore extinction risk and management?. PloS one, 8(2), e58060..

Devenish-Nelson, E.S., Harris, S., Soulsbury, C.D., Richards, S.A., Stephens, P.A., $2013 b$. Demography of a carnivore, the red fox, Vulpes vulpes: what have we learnt from 70 years of published studies? Oikos 122, 705-716.

Dobzhansky, T., 1950. Evolution in the tropics. Am. Scientist 38, 208-221.

Dugdale, H.L., Pope, L.C., Newman, C., Macdonald, D.W., Burke, T., 2011. Age-specific breeding success in a wild mammalian population: selection, constraint, restraint and senescence. Mol. Ecol. 20, 3261-3274. 
Reproductive senescence in the red fox

Elmeros, M., Pedersen, V., Wincentz, T.L., 2003. Placental scar counts and litter size estimations in ranched red foxes (Vulpes vulpes). Mamm. Biol. 68, 391-393.

Englund, J., 1970. Some aspects of reproduction and mortality rates in Swedish foxes (Vulpes vulpes), 1961 - 63 and 1966 - 69. Sweden Wildlife 8, 1-82.

Ericsson, G., Wallin, K., Ball, J.P., Broberg, M., 2001. Age-related reproductive effort and senescence in free-ranging moose, Alces alces. Ecology 82, 1613-1620.

Finn, C.A., 1977. The implantation reaction. In: Wynn, R.M., (Eds.), Biology of the uterus. Plenum Press, New York, pp. 245-308.

Gaillard, J.-M., Pontier, D., Allainé, D., Lebreton, J.D., Trouvilliez, J., Clobert, J., 1989. An analysis of demographic tactics in bird and mammals. Oikos 56, 59-76.

Gaillard, J.-M., Allaine, D., Pontier, D., 1994. Senescence in natural populations of mammals: a reanalysis. Evolution 48, 509-516.

Gaillard, J.-M., Lemaître, J.-F., Berger, V., Bonenfant, C., Devillard, S., Douhard, M., Gamelon, M., Plard, F., Lebreton, J.-D., 2016. Life Histories, Axes of Variation. In: Kliman, R.M., (Eds.), Encyclopedia of Evolutionary. Biology. Oxford: Academic Press. vol. 2, pp. 312-323.

Gittleman, J.L., 1986. Carnivore life history patterns: Allometric, phylogenetic, and ecological associations. Am. Nat. 127, 744-771.

Grau, G.A., Sanderson, G.C., Rogers, J.P., 1970. Age determination of raccoons. J. Wildl. Manag. 34, 364-371.

Hanks, J., 1972. Reproduction of elephant, Loxodonta africana, in the Luangwa Valley, Zambia. J. Reprod. Fertil. 30, 13-26.

Harris, S., 1978. Age determination in the red fox (Vulpes vulpes) - an evaluation of technique efficiency as applied to as sample of suburban fixes. J. Zool. 184, 91-117. 
Reproductive senescence in the red fox

Harris, S. 1979. Age-related fertility and productivity in red foxes, Vulpes vulpes, in suburban London. J. Zool. 187, 195-199.

Harris, S., Smith, G.C., 1987. Demography of two urban fox (Vulpes vulpes) populations. J. Appl. Ecol. 24, 75-86.

Harris, S., Cresswell, W.J., Cheeseman, C.L., 1992. Age determination of badgers (Meles meles) from tooth wear: the need for a pragmatic approach. Comm. Mamm. Soc. 65, 679684.

Harvey, P.H., Clutton-Brock, T.H., 1985. Life history variation in Primates. Evolution 39, $559-581$.

Hewison, A.J.M., Gaillard, J.-M., 2001. Phenotypic quality and senescence affect different components of reproductive output in roe deer. J. Anim. Ecol. 70, 600-608.

Heydon, M.J., Reynolds, J.C., 2000. Demography of rural foxes (Vulpes vulpes) in relation to cull intensity in three contrasting regions of Britain. J. Zool. 251, 265-276.

Jones, O.R., Gaillard, J.M., Tuljapurkar, S., Alho, J.S., Armitage, K.B., Becker, P.H., Bize, P., Brommer, J., Charmantier, A., Charpentier, M., Clutton-Brock, T., Dobson, F.S., FestaBianchet, M., Gustafsson, L., Jensen, H., Jones, C.G., Lillandt, B.G., McCleery, R., Merilä, J., Neuhaus, P., Nicoll, M.A.C, Norris, K., Oli, M.K., Pemberton, J., Pietiäinen, H., Ringsby, T.H., Roulin, A., Saether, B.-E., Setchell, J.M., Sheldon, B.C., Thompson, P.M., Weimerskirch, H., Wickings, J. E., Coulson, T., 2008. Senescence rates are determined by ranking on the fast-slow life-history continuum. Ecol. Letters 11, 664-673.

King, C.M., 1991. A review of age determination methods for the stoat Mustela erminea. Mamm. Rev. 2, 31-49.

Kirkwood, T.B.L., 1977. Evolution of ageing. Nature 270, 301-304.

Kirkwood, T.B.L., Rose, M.R., 1991. Evolution of senescence: late survival sacrificed for reproduction. Phil. Trans. Royal Soc. London B, Biol. Sci. 332, 15-24. 
Reproductive senescence in the red fox

Kirkwood, T.B.L., Austad, S.N., 2000. Why do we age? Nature 408, 233-238.

Lack, D., 1947. The significance of clutch size. Ibis 89, 302-352.

Lemaître, J.-F., Berger, V., Bonenfant, C., Douhard, M., Gamelon, M., Plard, F., Gaillard, J.M., 2015. Early-late life trade-offs and the evolution of ageing in the wild. Proc. Royal Soc. London B, Biol. Sci. 282, 02-09.

Lieury, N., Ruette, S., Devillard, S., Drouyer, F., Baudoux, B., Millon, A., 2015.

Compensatory Immigration Challenges Predator Control: An Experimental EvidenceBased Approach Improves Management. J. Wildl. Manag. 79, 425-434.

Lindström, E.R., 1989. Food limitation and social regulation in a red fox population. Ecography 12, 70-79.

Lindström, E.R., 1994. Placental scar in the red fox (Vulpes vulpes L.) revisited. Z Saugetierkd. 59, 169-173.

Marlow, N.J., Thomson, P.C., Algar, D., Rose, K., Kok, N.E., Sinagra, J.A., 2000. Demographic characteristics and social organisation of a population of red foxes in a rangeland area in Western Australia. Wildl. Res. 27, 457-464.

Massot, M., Clobert, J., Montes-Poloni, L., Haussy, C., Cubo, J., Meylan, S., 2011. An integrative study of ageing in a wild population of common lizards. Funct. Ecol. 25, 848858.

Matson, G.M., Matson, J., 1993. Progress in cementum aging of martens and fishers. Special Report no. 931. Matson's Laboratory Ed., Milltown, MT.

McDonald, T.L., White, G.C., 2010. A Comparison of regression models for small counts. J. Wildl. Manag. 74, 514-521.

McIlroy, J., Saunders, G., Hinds, L.A., 2001. The reproductive performance of female red foxes, Vulpes vulpes, in central-western New South Wales during and after a drought. Can. J. Zool. 79, 545-553. 
Reproductive senescence in the red fox

Melero, Y., Robinson, E., Lambin, X., 2015. Density- and age-dependent reproduction partially compensates culling efforts of invasive non-native American mink. Biol. Invasions 17, 2645-2657.

Nussey, D.H., Kruuk, L.E.B., Donald, A., Fowlie, M., Clutton-Brock, T.H., 2006. The rate of senescence in maternal performance increases with early-life fecundity in red deer. Ecol. Lett. 9, 1342-1350.

Nussey, D.H., Coulson, T., Festa-Bianchet, M., Gaillard, J.-M., 2008. Measuring senescence in wild animal populations: towards a longitudinal approach. Funct. Ecol. 22, 393-406.

Nussey, D.H., Froy, H., Lemaitre, J.-F., Gaillard, J.-M., Austad, S.N., 2013. Senescence in natural populations of animals: widespread evidence and its implications for biogerontology. Ageing Res. Rev. 12, 214-225.

Packer, C., Herbst, L., Pusey, A.E., Bygott, J.D., Hanby, J.P., Cairns, S.J., Borgerhoff Mulder M., 1988. Reproductive success of lions. In: Clutton-Brock, T.H. (Eds.), Reproductive success: studies of individual variation in contrasting breeding systems. University of Chicago Press, Chicago, pp. 363-383.

Promislow, D.E.L., Harvey, P.H., 1990. Living fast and dying young: A comparative analysis of life-history variation among mammals. J. Zool. 220, 417-437.

Promislow, D.E.L. 1991. Senescence in Natural Populations of Mammals: A Comparative study. Evolution 45, 1869-1887.

R Development Core Team, 2012. R: A language and environment for statistical computing. R Foundation for Statistical Computing, ISBN 3-900051-07-0, Vienna, Austria

Read, A.F., Harvey, P.H., 1989. Life history differences among the eutherian radiations. J. Zool. 219, 329-353. 
Reproductive senescence in the red fox

Reid, J.M., Bignal, E.M., Bignal, S., McCracken, D.I., Monaghan, P., 2003. Age-specific reproductive performance in red-billed choughs Pyrrhocorax pyrrhocorax: patterns and processes in a natural population. J. Anim. Ecol. 72, 765-776.

Ruette, S., Albaret, M., 2011. Reproduction of the red fox Vulpes vulpes in western France: does staining improve estimation of litter size from placental scar counts? Eur. J. Wildl. Res. 57, 555-564.

Schwartz, C.C., Keating, K.A., Reynolds, H.V., Barnes, V.G., Sellers, R.A., Swenson, J.E., Miller, S.D., McLellan, B.N., Keay, J., McCann, R., Gibeau, M., Wayne, F., Wakkinen, W.F., Richard, D.M., Kasworm, W., Smith, R., Herrero, S., 2003. Reproductive maturation and senescence in the female brown bear. Ursus 14, 109-111.

Sharp, S.P., Clutton-Brock, T.H., 2010. Reproductive senescence in a cooperatively breeding mammal. J. Anim. Ecol. 79,176-83.

Stearns, S.C., 1983. The influence of size and phylogeny on patterns of covariation among life-history traits in the mammals. Oikos 41, 173-187.

Van de Pol, M., Verhulst, S., 2006. Age-dependent traits: a new statistical model to separate within and between individual effects. Am. Nat. 167, 766-773.

Van Horn R.C., McElhinny, T.L., Holekamp, K.E., 2003. Age estimation and dispersal in the spotted hyena (Crocuta crocuta). J. Mammal. 84, 1019-1030.

Wood, S., 2006. Generalized additive models: an introduction with R, Chapman Hall/CRC.

Vos, A.C., 1994. Reproductive performance of the red fox, Vulpes vulpes, in GarmishPartenkirchen, Germany, 1987-1992. Z. Saugetierkd. 59, 326-331.

Zuur, A. F., Ieno, E. N., Walker, N. J., Saveliev, A. A., and Smith, G. M., 2009. Mixed effects models and extensions in ecology with R. Springer, New York, New York, USA. 
Reproductive senescence in the red fox

Table 1. Summary of data sampling, with number of necropsied vixens collected in Champagne and Brittany regions between 2002 and 2011 from which a proxy of litter size (embryos + placental scars in brackets) could be measured $(N=755)$.

\begin{tabular}{|c|c|c|c|c|c|c|c|c|c|c|c|}
\hline & Year & & & & & & & & & & \\
\hline Region & 2002 & 2003 & 2004 & 2005 & 2006 & 2007 & 2008 & 2009 & 2010 & 2011 & Total \\
\hline Brittany & $\begin{array}{l}111 \\
(79+32) \\
\end{array}$ & $\begin{array}{l}66 \\
(44+22) \\
\end{array}$ & $\begin{array}{l}72 \\
(41+31) \\
\end{array}$ & $\begin{array}{l}70 \\
(37+33) \\
\end{array}$ & $\begin{array}{l}77 \\
(58+19) \\
\end{array}$ & $\begin{array}{l}40 \\
(39+1) \\
\end{array}$ & & & & & 436 \\
\hline Champagne & & & & & $\begin{array}{l}62 \\
(20+42)\end{array}$ & $\begin{array}{l}69 \\
(27+42)\end{array}$ & $\begin{array}{l}60 \\
(16+44)\end{array}$ & $\begin{array}{l}51 \\
(15+36)\end{array}$ & $\begin{array}{l}36 \\
(10+26)\end{array}$ & $\begin{array}{l}41 \\
(8+33)\end{array}$ & 319 \\
\hline
\end{tabular}


Reproductive senescence in the red fox

Table 2. Mean litter size using placental scars count ( \pm standard deviation, SD) and embryos counts ( \pm standard deviation, SD) by age class, with the number of necropsied vixens (n) collected in Champagne and Brittany regions between 2002 and 2011.

\begin{tabular}{lllll} 
Age class & Mean embryos counts $( \pm \mathrm{SD})$ & $\mathrm{n}$ & Mean placental scars count $( \pm \mathrm{SD})$ & $\mathrm{n}$ \\
\hline 1 & $4.6 \pm 1.3$ & 172 & $4.3 \pm 1.3$ & 151 \\
2 & $4.9 \pm 1.3$ & $4.8 \pm 1.3$ & 79 \\
3 & $5.3 \pm 1.7$ & 45 & $4.7 \pm 1.5$ & 53 \\
4 & $5.3 \pm 1.5$ & 45 & $5.0 \pm 1.3$ & 35 \\
5 & $5.5 \pm 1.7$ & 22 & $4.7 \pm 1.3$ & 23 \\
6 & $5.6 \pm 1.4$ & 11 & $4.3 \pm 1.2$ & 9 \\
7 & $4.3 \pm 1.7$ & 4 & $2.6 \pm 1.4$ & 7 \\
8 & $5.8 \pm 1.0$ & 4 & $2.5 \pm 0.7$ & 2 \\
9 & $3.7 \pm 1.5$ & 3 & 3.0 & 1 \\
10 & 5.0 & 1 & 4.0 & 1 \\
\hline Total & $4.9 \pm 1.4$ & 394 & $4.5 \pm 1.4$ & 361 \\
\hline & & & & \\
\hline
\end{tabular}


Reproductive senescence in the red fox

Table 3. Selection among GAMMs investigating the variation in litter size in the red fox. A: Model selection of the spatio-temporal random effects associated with Year, Region (Brittany and Champagne) and Site (3 sites in Britanny, 2 in Champagne), using Restricted Maximum Likelihood. The bars indicate the addition of a random effect of the 'Year' on the intercept, 1|Year, or of the site on the slope vixen age, Age|Site. The parameterization s(Age)×Type denotes that the non-linear effect of vixen Age was modelled independently for each 'Type' of the litter size proxy (placental scars or embryos). B: Model selection of the fixed-effects (using Maximum Likelihood). Models are sorted by the number of parameters $(K)$. The loglikelihood value (LogLik) and the difference in AICc with the best model ( $\triangle A I C c)$ are presented (best models in bold). The best model is selected for predictions and estimations.

\begin{tabular}{|c|c|c|c|}
\hline A. Selection of random effects & $K$ & LogLik & $\triangle A I C c$ \\
\hline s(Age) $\times$ Type + Age $\mid$ Site $+1 \mid$ Year & 11 & -1304.02 & 2.84 \\
\hline s(Age) $\times$ Type + 1|Site + 1|Year & 9 & -1304.56 & 0.00 \\
\hline $\mathrm{s}($ Age $) \times$ Type $+1 \mid$ Region $+1 \mid$ Year & 9 & -1305.48 & 1.77 \\
\hline $\mathrm{s}($ Age $) \times$ Type $+1 \mid$ Year & 8 & -1307.89 & 4.59 \\
\hline s(Age) $\times$ Type & 7 & -1321.56 & 29.32 \\
\hline
\end{tabular}

\begin{tabular}{llll}
\hline s(Age) $\times$ Type + 1|Site + 1|Year & $\mathbf{9}$ & $\mathbf{- 1 3 0 1 . 8 8}$ & $\mathbf{0 . 0 0}$ \\
$\mathrm{s}($ Age $)+$ Type $+1 \mid$ Site $+1 \mid$ Year & 7 & -1306.28 & 5.19
\end{tabular}


Reproductive senescence in the red fox

Figure 1. Location showing the sites where the landscape-scale culling experiments of red foxes took place. Green, white and grey areas indicates forest, crops and urban areas respectively.

Figure 2. Variation in litter size of the red fox in relation to the age of vixens (in years) derived from hunting bags. Distinction was made between litter size counted from number of embryos (in grey) or from the number of placental scars (in black). Dot size is proportional to sample size (total number indicated at the top of the graph, both types of counts combined). Lines represent GAMM predictions (plain) and their associated standard error (dashed). 
Reproductive senescence in the red fox

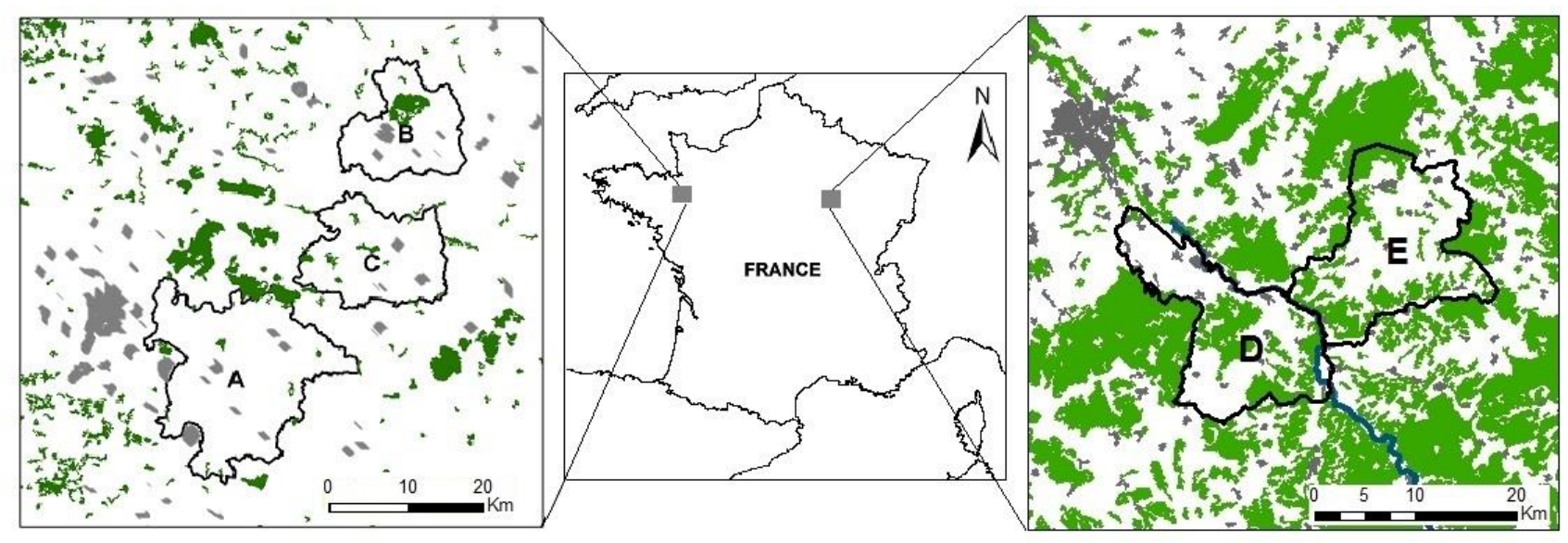

Fig. 1 
Reproductive senescence in the red fox

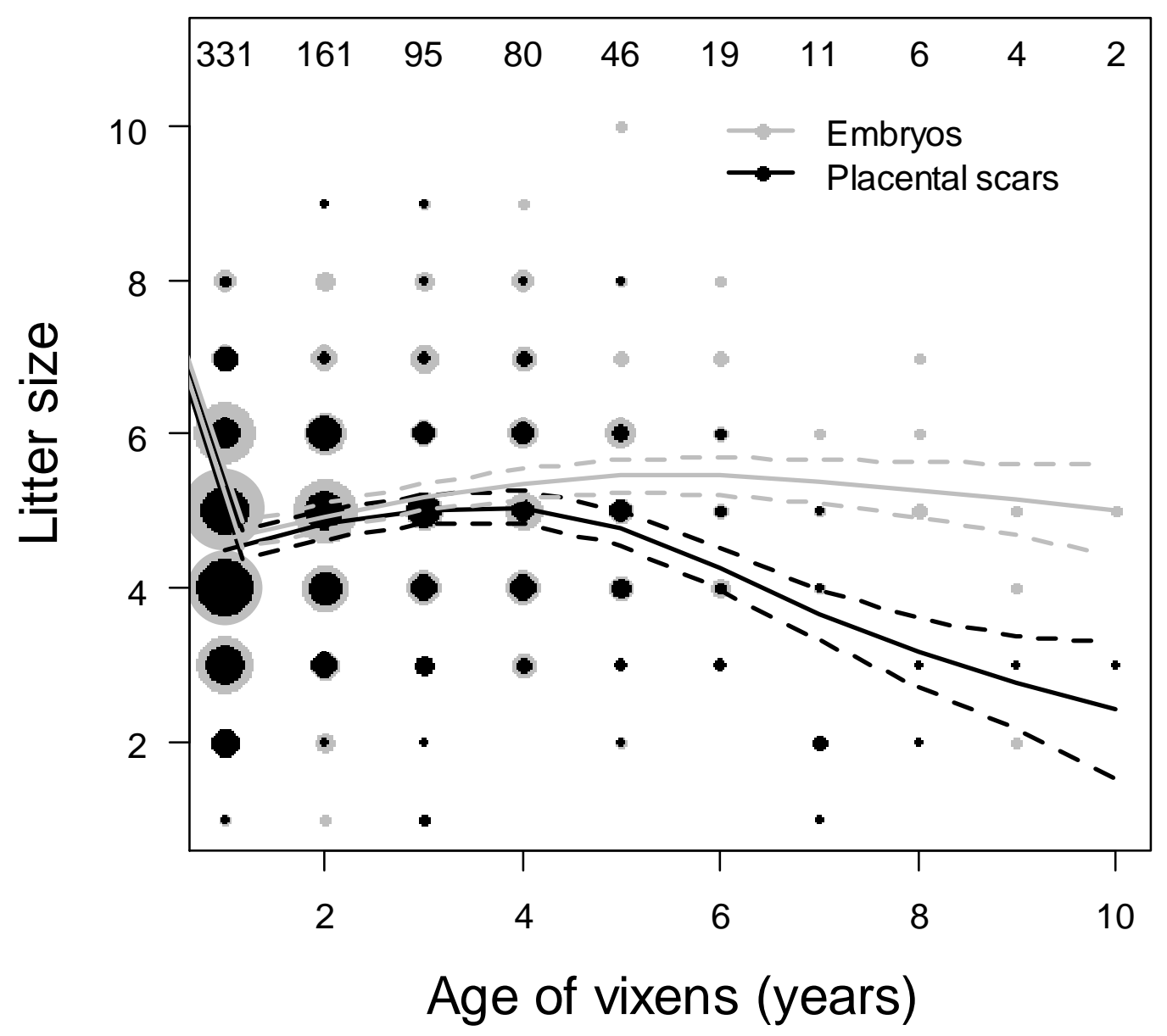

Fig. 2 